\title{
Clinical study on VATS combined mechanical ventilation treatment of ARDS secondary to severe chest trauma
}

\author{
YONGJUN QI \\ Department of Thoracic Surgery, Beijing Mentougou Hospital, Beijing 102300, P.R. China
}

Received January 12, 2016; Accepted May 17, 2016

DOI: $10.3892 /$ etm.2016.3355

\begin{abstract}
The aim of the study was to investigate the clinical effects of microinvasive video-assisted thoracoscopic surgery (VATS) combined with mechanical ventilation in the treatment of acute respiratory distress syndrome (ARDS) secondary to severe chest trauma. A total of 62 patients with ARDS secondary to severe chest trauma were divided into the observation and control groups. The patients in the observation groups were treated with VATS combined with early mechanical ventilation while patients in the control group were treated using routine open thoracotomy combined with early mechanical ventilation. Compared to the controls, the survival rate of the observation group was significantly higher. The average operation time of the observation group was significantly shorter than that of the control group, and the incidence of complications in the perioperative period of the observation group was significantly lower than that of the control group $(\mathrm{p}<0.05)$. The average application time of the observation group was significantly shorter than that of the control group, and the incidence of ventilator-associated complications was significantly lower than that of the control group ( $\mathrm{p}<0.05)$. In conclusion, a reasonable understanding of the indications and contraindications of VATS, combined with early mechanical treatment significantly improved the success rate of the treatment of ARDS patients secondary to severe chest trauma and reduced the complications.
\end{abstract}

\section{Introduction}

The mortality rate resulting from traffic accidents annually has reached up to $20 \%$, and is second to the mortality rate of chronic diseases such as cardiovascular and cerebrovascular diseases (?). This mortality rate of acute respiratory distress

Correspondence to: Dr Yongjun Qi, Department of Thoracic Surgery, Beijing Mentougou Hospital, 10 Hetanqiaodong Street, Beijing 102300, P.R. China

E-mail: yongjunqi@yeah.net

Key words: microinvasive video-assisted thoracoscopic surgery, mechanical ventilation, chest trauma, acute respiratory distress syndrome syndrome (ARDS), which is secondary to severe chest trauma has reached $60 \%$. The disease is serious, complex, and progresses very rapidly (1). Although the assisted mechanical ventilation therapy and the more effective lung protective ventilation strategy may significantly improve the curative rate of severe hypoxia and dyspnea, the success of the treatment is dependent on the timely, proper, and effective treatment of basic diseases including severe chest trauma and complex injuries $(2,3)$. As microinvasive video-assisted thoracoscopic surgery (VATS) becomes increasingly utilized in the Department of Thoracic Surgery, the clinical indications become increasingly expanded, the technology and instruments employed more advanced, and the significance of VATS in the emergency treatment of severe chest trauma has become increasingly pervasive (4).

The aim of the present study was to investigate the clinical effects of VATS combined with mechanical ventilation in the treatment of ARDS secondary to severe chest trauma.

\section{Patients and methods}

Patients. In total, 62 patients with ARDS secondary to severe chest trauma were included in the present study. The patients were divided into the observation $(n=32)$ and control $(n=30)$ groups. Patients with any one of the following symptoms was considered as severe chest trauma (5): i) Flail chest resulting from multiple rib fractures; ii) hematopneumothorax of moderate volume or above; iii) severe pulmonary contusion; iv) cardiac vascular injury; and v) trachea bronchial rupture. The Abbreviated Injury Scale (AIS) and Injury Severity Score (ISS) (AIS-ISS score) was $\geq 3$. Diagnostic criteria for ARDS were provided by Chiumello et al (6), which includes progressive dyspnea, respiratory rate of $>35$ times $/ \mathrm{min}, \mathrm{pO}_{2}$ $<60 \mathrm{mmHg}$, and $\mathrm{pO}_{2} / \mathrm{FiO}_{2} \leq 200 \mathrm{mmHg}$; with chest X-ray showing patchy or flocculent shadows in lung. The exclusion criteria were: i) Patients with severe craniocerebral injury, traumatic shock, infection, consciousness disorder, multiple fractures, severe spinal cord injury, with expected survival $<1$ month; ii) patients with chest deformity, previous chest surgery, malignant tumor, severe hypertension, heart disease, and intolerability to surgery and anesthesia risks; iii) patients with failed assisted mechanical ventilation, irreformable hypoxia, central paralysis, poor recovery under ventilator, and ventilator dependence; and iv) patients that suspended treatmentor had incomplete clinical data or poor compliance. 
The observation group included 20 men and 12 women, with an age range of 37-66 years, and average of $48.5 \pm 12.4$ years. The onset time was from 1 to $12 \mathrm{~h}$ with an average of $6.8 \pm 1.6 \mathrm{~h}$. There were 18 cases of flail chest, 7 cases of hemopneumothorax, 6 cases of pulmonary contusion, 1 case of other symptom, 2 cases combined with craniocerebral injury, 6 cases with abdominal injury, and 5 cases with pelvic injury. The control group included 17 men and 13 women, with an age range of $35-70$ years, and average of $49.4 \pm 13.3$ years. The onset time was from 1.5 to $10 \mathrm{~h}$, with an average of $6.5 \pm 1.4 \mathrm{~h}$. The control group included 16 cases of flail chest, 5 cases of hemopneumothorax, 7 cases of pulmonary contusion, 2 cases of other symptom, 1 cases combined with craniocerebral injury, 5 cases with abdominal injury, and 6 cases with pelvic injury. The differences with regard to baseline data for the two groups were not statistically significant $(\mathrm{p}>0.05)$.

Treatment methods. The patients in the observation group were treated with VATS combined with early mechanical ventilation and the patients in the control group only using routine open thoracotomy combined with early mechanical ventilation. Within $24 \mathrm{~h}$ of onset, artificial respiratory passages were established on the patients and connected to a ventilator (Galileo 150 type; Hamilton Medical AG, Bonaduz, Switzerland). Lung protective ventilation strategy was taken as the ventilation mode: synchronized intermittent mandatory ventilation (SIMV) + positive end-expiratory pressure (PEEP), tidal volume of $6-8 \mathrm{ml} / \mathrm{kg}$. The best PEEP was set by the expiratory phase PV curve ranging from 5 to $15 \mathrm{~cm} \mathrm{H}_{2} \mathrm{O}$, with a frequency of 12-18 times/min, I/E of 1:1.5, and $\mathrm{FiO}_{2}$ of $40-60 \%$. Patients with ventilator antagonism were treated using muscle relaxation and sedative drugs. The ventilator parameters were adjusted as required as per the changes of patient's conditions and monitoring of their blood gas analysis. The weaning indications were: the disease was controlled, consciousness became clear, and spontaneous breathing was recovered, respiratory rate of $<25$ times $/ \mathrm{min}$, tidal volume of $>6 \mathrm{ml} / \mathrm{kg}, \mathrm{FiO}_{2}$ of $<0.6$, gradually decreasing the PEET to 0 .

Central venous pressure was closely monitored, the balance of intake and output volume was balanced, airway wetting liquid including 4000 units $\alpha$-chymotrypsinum, $2 \mathrm{mg}$ dexamethasone, $8 \times 10^{5}$ units gentamycin and $50 \mathrm{ml}$ normal saline (purchased from Yangtze River Pharmaceutical, Taizhou, Jiangsu, China) was administered using a micropump (Bio-Chem Valve Company, NJ, USA) to guarantee accurate medication, management of the respiratory tract was strengthened and secretions of the respiratory tract were removed in a timely manner. For patients with relatively more airway secretion, bedside bronchoscopy sputum suction and bronchoalveolar lavage were used for treatment. In addition, deep-seated sputum and secretion were sent for sputum examination, and patients were administered with highly effective broad-spectrum antibiotics (ceftriaxone sodium; Yangtze River Pharmaceutical) according to the drug sensitivity results. The blood gas analysis was reviewed, and the ventilator parameters were adjusted as required to prevent acid-base imbalance. The patients were also administered with total parenteral or enteral nutrition and gastrointestinal stress ulcer prevention treatment.
For the VATS operations, a double-lumen tube (Tyco International Ltd., NY, USA) was applied for intubation. After general anesthesia, the patients were maintained in a lateral position and single lung ventilation was conducted. A $1.5-\mathrm{cm}$ incision was made on the 7 th or 8 th rib at the midaxillary line of the affected side and the tube was inserted into the thoracoscope (Richard-wolf Company, Berlin, Germany) to detect the condition inside the thoracic cavity. The location was determined according to the position of thoracoscopic exploration (for the chest trauma patients with pleural effusion, first hematocele was exhausted through the incision and thorax washing was performed) and preoperative chest X-ray, CT or MRI lesion. An incision of 1.5-2.5 cm was made between the 4th and 6 th rib from the anterior to the posterior axillary line, and an incision of diaphragmatic injury was made between the 7 th and 9 th rib. Another $0.5-1 \mathrm{~cm}$ incision was made to the same ribs with the operation incision between the posterior axillary line and linea scapularis serving as the auxiliary incision. If needed, the two incisions were connected into a $6-8 \mathrm{~cm}$ thoracoscope auxiliary incision, distracted by a small distracter and the injury site was repaired under direct vision. Hemorrhage resulting from vascular injury between the ribs was stopped by a titanium clip or stitch around the rib. Lung tissue injury was repaired under direct vision or using an automatic cutter stapler to excise partial lung. The diaphragm injuries were repaired by silk suture, and the rib fracture was treated by suspending a cross-rib wire line in ' $U$ ' shape. Pulmonary lobectomy was subject to conventional method by dissecting the porta pulmonis and fissure lung, an automatic cutter stapler or suture was used to seal the vascular and fissure lung, and the bronchus was treated with a residual end closure device or open suture. Following treatment, if the wounded surface of the lung showed lair leakage or errhysis, the wounded surface was sutured using a 3-0 prolene line, and fibrin glue was sprayed if necessary. Subsequently, $9 \mathrm{~g} / \mathrm{l}$ of isotonic saline solution was used to wash the thoracic cavity and any leakage was closely monitored. A five lobe retractor (Zhongxi Yuanda Science and Technology Co., Ltd., Beijing, China) was used to expose the pulmonary surface, gradually expand the lung and check repeatedly. However, conventional thoracotomy was performed when VATS was impossible.

Observation index. The survival rate at 1 month, average time of operation, incidence of complications in the perioperative period, average application time and incidence of ventilator-associated complications was compared between the two groups of patients. Perioperative complications included hemorrhagic shock, infection, extubation difficulty, definite nerve and respiratory muscle injuries. Ventilator-associated complications included ventilator-associated pneumonia and ventilator-induced lung injury.

Statistical analysis. SPSS 20.0 software (IBM, Armonk, NY, USA) was applied for statistical analysis. Data were presented as means \pm standard deviation. An independent sample t-test was used in the comparison between groups. The enumeration data were presented by case or as a percentage, and $\chi^{2}$ test was applied in intra-group comparisons. $\mathrm{P}<0.05$ was considered to indicate statistically significance. 
Table I. Comparisons of operation-related indices.

\begin{tabular}{|c|c|c|c|c|c|c|c|c|}
\hline Group & Case & $\begin{array}{c}\text { Survival rate } \\
\mathrm{n}(\%)\end{array}$ & $\begin{array}{l}\text { Operation } \\
\text { time }(\min )\end{array}$ & $\begin{array}{l}\text { Hemorrhagic } \\
\text { shock }\end{array}$ & Infection & $\begin{array}{l}\text { Decannulation } \\
\text { difficulty }\end{array}$ & $\begin{array}{c}\text { Nerve and } \\
\text { respiratory } \\
\text { muscle damage }\end{array}$ & $\begin{array}{c}\text { Perioperative } \\
\text { complications, n }(\%)\end{array}$ \\
\hline Control & 30 & $14(46.7)$ & $95.7 \pm 21.6$ & 4 & 3 & 3 & 3 & $13(43.3)$ \\
\hline Observation & 32 & $23(71.9)$ & $62.4 \pm 18.5$ & 2 & 1 & 2 & 1 & $6(18.8)$ \\
\hline $\mathrm{t}\left(\chi^{2}\right)$ & & 4.089 & 5.628 & & & & & 4.403 \\
\hline P-value & & 0.043 & 0.032 & & & & & 0.036 \\
\hline
\end{tabular}

Table II. Comparisons of respiratory indices.

\begin{tabular}{|c|c|c|c|c|c|}
\hline Group & Case & Ventilator application time (days) & VAP & VILI & Ventilator associated complications \\
\hline Control group & 30 & $8.7 \pm 1.3$ & 6 & 3 & $9(30.0)$ \\
\hline Observation group & 32 & $5.6 \pm 1.2$ & 2 & 1 & $3(9.4)$ \\
\hline $\mathrm{t}\left(\chi^{2}\right)$ & & 5.947 & & & 4.220 \\
\hline P-value & & 0.028 & & & 0.040 \\
\hline
\end{tabular}

VAP, ventilator-associated pneumonia; VILI, ventilator-induced lung injury.

\section{Results}

Comparisons of operation-related indices. The survival rate of the observation group was significantly higher than that of the control group, and the average operation time of the observation group was significantly shorter than that of the control group. The incidence of complications in the perioperative period of the observation group was significantly lower than that of the control group $(\mathrm{p}<0.05)$ (Table I).

Comparisons of respiratory indices. The average application time of the observation group was significantly shorter than that of the control group, and the incidence of ventilator-associated complications was significantly lower than that of the control group $(\mathrm{p}<0.05)$ (Table II).

\section{Discussion}

Severe chest trauma leads to pulmonary contusion or traumatic wet lung, which causes pulmonary hemorrhage, interstitial edema, and reduced pulmonary compliance (7). These conditions result in ARDS with diffuse injury of pulmonary capillary and enhanced permeability as its basis; pulmonary edema, transparent membrane formation, with pulmonary atelectasis as its major pathological changes; and progressive respiratory distress and refractory hypoxia as its clinical characteristics (8). Flail chest, chest wall abnormal breathing, and mediastinal swing further aggravated the respiratory and circulatory disturbances. Secondary ARDS is direct and rapid, and progression from acute lung injury to ARDS is more rapid (9). Most ARDS occur within $24 \mathrm{~h}$ after severe chest trauma, and the mortality rate reaches up to $60 \%$.

The lung-protective ventilatory strategy (LPVS) was introduced to circumvent a series of complications such as volutrauma, pulmonary barotrauma, shear stress trauma, and biological trauma. At present, it is commonly used in treatment of refractory hypoxia incurred from lung capacity reduction, compliance decrease, and a Qs/Qt increase resulting from ALI/ARDS, leading to ARDS extensive mini-foci pulmonary atelectasis or alveolar collapse. It is considered as the third milestone of LPVS (10).

SIMV refers to forced ventilation synchronized with autonomous respiration, that is, the mandatory ventilation of the ventilator synchronized with the extent, rhythm, and time phase of breathing, without obvious antagonism phenomenon (11). SIMV has the following three advantages: i) SIMV reduces the discomfort of the patients at ventilation, autonomous respiration could be against the ventilator, and may reduce the patients' anxiety and fear; ii) SIMV reduces the airway pressure and prevents the ventilator from atrophy or movement disorders, avoiding withdrawal difficulty; iii) SIMV reduces the influence of the ventilator on the cardiovascular system. At present, it is commonly believed that on the premise of ensuring the amount of basic ventilation, it is reasonable that a ventilation strategy with lower tidal volumes may control the platform pressure under $28 \mathrm{~cm}$ $\mathrm{H}_{2} \mathrm{O}$ (12), which may, not only prevent the pulmonary alveoli from excessive expansion, but also avoid it from exceeding the strain threshold value of the lung. In the present study, the tidal volume was set at $6-8 \mathrm{ml} / \mathrm{kg}$, the airway peak inspiratory pressure was maintained at $\leq 3.43 \mathrm{kPa}$, and the pressure trauma resulted from mechanical ventilation was reduced.

PEEP maintained the expansion of pulmonary alveoli, reduced shear stress trauma caused by alveolar collapse and recruitment. In addition, it overcame the softening and floating chest walls, favorable for the healing of rib fractures and the stability of the chest wall, reduced the intrapulmonary shunt while decreasing the osmosis of liquid inside blood capillaries to pulmonary alveoli under pneumonedema, improved the ventilation/blood flow ratio, and significantly ameliorated the 
$\mathrm{pO}_{2}$. However, when the PEEP was extremely high, it affected the hemodynamics (13). Excessive expansion resulted in alveolar rupture and pressure trauma, including pneumothorax, and subcutaneous emphysemam. In the present study, $5 \mathrm{~cm}$ $\mathrm{H}_{2} \mathrm{O}$ was taken as the initial pressure. The volume was gradually increased until optimal 5-15 $\mathrm{cm} \mathrm{H}_{2} \mathrm{O}$ was achieved. The negative results of large-scale clinical trials and the multiple optimal PEEP setting methods at present have indicated that an individualized PEEP scheme is required for the PEEP value of ARDS patients, or it would be impossible to protect the lung of ARDS patients (14). The method of pressure-volume (P-V) curve achieved positive results in the clinic. An upward $\mathrm{P}-\mathrm{V}$ curve indicates that in the process of inhalation, some pulmonary alveoli is being increasingly recruited and the compliance of lung increasingly improved. By contrast, a downward P-V curve indicates that in the process of inhalation, some pulmonary alveoli are excessively expanding and the compliance of lung is increasingly exacerbated. In addition, a straight line indicates that in the process of inhalation, there is no sunken alveolar recruitment or excessive expansion following alveolar recruitment, while the compliance of lung exhibited no change. Therefore, alveolar recruitment is the best when the P-V curve has levelled off (15).

Thoracoscopy has some advantages in the treatment of thoracic trauma. It is a minimally invasive surgical procedure that is free from rib excision or distraction. It keeps respiratory muscle intact, and does not affect coughing or sputum excretion. The amount of bleeding during surgery, the incidence of complications of chest incision, and postoperative wound pain are all reduced. Recovery time after operation is less, and patients are discharged from the hospital earlier (16). VATS has been widely used in various types of surgical diseases. However, compared with conventional thoracotomy, VATS has some shortcomings (17). Therefore, it would be quite significant to understand the surgical indications of the patients.

Except for patients in critical condition, with poor antishock effect (always accompanied with injury hemorrhage of heart or great vessels) who required immediate thoracotomy, almost all chest trauma patients who require surgical treatment are eligible for diagnosis and treatment via thoracoscopy. Freeman et al deemed that VATS has obvious advantages in the diagnosis and treatment of diaphragmatic injuries caused by penetrating injury (18). Thoracoscopy allows surgeons to directly detect the diaphragmatic injuries, thus providing an exact basis for the thoracic exploration of patients with diaphragmatic or combined thoracic-abdominal injuries, reducing unnecessary thoracic exploration. In treating with flail chest under the monitoring of thoracoscope, surgeons identify the right location by pressing the chest wall with finger and use steel wire to suture the fracture of rib in ' $U$ ' shape, repair the softening region of the chest wall, and restore it to its original location (18). Following surgery, the abnormal respiratory movement in the chest wall is completely eliminated, and the respiratory functions of the patient are significantly improved. Within 1-3 days after surgery, the patients are taken off the ventilator. Compared with the ventilation treatment which depended on pressure bandaging of the chest wall, thoracoscopy has several advantages. The patients are separated from the ventilator earlier and recover more quickly. This type of treatment incision wounds resulting from thoracotomy on the fractured intercostal vascular retraction pleura are avoided, as reported by Lowdermilk and Naunheim (19).

Approximately 6-20\% VATS require conversion to laparotomy (20). The common reasons include the fact that pleural adhesion is extensive and close, resulting in insufficient operation space; injury hemorrhage of relatively large vessels from chest trauma, such as injury hemorrhage of pulmonary parenchymal vessels and cardiac vessels close to hilus pulmonis; a larger range of diaphragmatic lacerations; uncontrollable hemorrhage caused by accidental injuries on blood vessels or surrounding tissues and organs during surgery and thoracotomy; and single lung ventilation could not be maintained during surgery (21). Hemorrhage, re-expansion of pulmonary edema, pulmonary leakage are common complications of VATS (22). They are closely associated with the selection of case and operation technology. Intercostal vessels, chest wall adhesive band fracture, and accidental injuries on sites surrounding the surgical site, or the careless detection on the bleeding sites of chest trauma are the major causes for intra- or post-operative hemorrhage.

In the present study, we found that compared to the control group, the survival rate of the observation group was significantly improved, the average operation time and incidence of complications in the perioperative period was significantly reduced, the average application time was significantly shortened, and the incidence of ventilator-associated complications was significantly decreased. These differences were statistically significant. Thus, the indications and contraindications of VATS, combined with early mechanical treatment significantly improved the success rate of the treatment of ARDS patients secondary to severe chest trauma and reduce the complications. Consequently, it has important application value in the clinic.

\section{References}

1. Duggal A, Perez P, Golan E, Tremblay L and Sinuff T: Safety and efficacy of noninvasive ventilation in patients with blunt chest trauma: a systematic review. Crit Care 17: R142, 2013.

2. Richter T and Ragaller M: Ventilation in chest trauma. J Emerg Trauma Shock 4: 251-259, 2011.

3. Unsworth A, Curtis K and Asha SE: Treatments for blunt chest trauma and their impact on patient outcomes and health service delivery. Scand J Trauma Resusc Emerg Med 23: 17, 2015.

4. Cao C, Manganas C, Ang SC and Yan TD: A systematic review and meta-analysis on pulmonary resections by robotic video-assisted thoracic surgery. Ann Cardiothorac Surg 1: 3-10, 2012.

5. Ehrnthaller C, Flierl M, Perl M, Denk S, Unnewehr H, Ward PA, Radermacher P, Ignatius A, Gebhard F, Chinnaiyan A, et al: The molecular fingerprint of lung inflammation after blunt chest trauma. Eur J Med Res 20: 70, 2015.

6. Chiumello D, Carlesso E, Cadringher P, Caironi P, Valenza F, Polli F, Tallarini F, Cozzi P, Cressoni M, Colombo A, et al: Lung stress and strain during mechanical ventilation for acute respiratory distress syndrome. Am J Respir Crit Care Med 178: 346-355, 2008.

7. Daurat A, Millet I, Roustan JP, Maury C, Taourel P, Jaber S, Capdevila $\mathrm{X}$ and Charbit J: Thoracic trauma severity score on admission allows to determine the risk of delayed ARDS in trauma patients with pulmonary contusion. Injury 47: 147-153, 2016.

8. Guo-shou Z, Xiang-jun B and Cheng-ye Z: Analysis of high risk factors related to acute respiratory distress syndrome following severe thoracoabdominal injuries. Chin J Traumatol 10: 275-278, 2007.

9. Kangelaris KN, Calfee CS, May AK, Zhuo H, Matthay MA and Ware LB: Is there still a role for the lung injury score in the era of the Berlin definition ARDS? Ann Intensive Care 4: 4, 2014. 
10. Chang SY, Dabbagh O, Gajic O, Patrawalla A, Elie MC, Talmor DS, Malhotra A, Adesanya A, Anderson HL III, Blum JM, et al; United States Critical Illness and Injury Trials Group: Lung Injury Prevention Study Investigators (USCIITG-LIPS): Contemporary ventilator management in patients with and at risk of ALI/ARDS. Respir Care 58: 578-588, 2013.

11. Singh PM, Borle A and Trikha A: Newer nonconventional modes of mechanical ventilation. J Emerg Trauma Shock 7: 222-227, 2014.

12. Cherpanath TG, Smeding L, Hirsch A, Lagrand WK, Schultz MJ and Groeneveld AB: Low tidal volume ventilation ameliorates left ventricular dysfunction in mechanically ventilated rats following LPS-induced lung injury. BMC Anesthesiol 15: 140, 2015.

13. Berngard SC, Beitler JR and Malhotra A: Personalizing mechanical ventilation for acute respiratory distress syndrome. J Thorac Dis 8: E172-E174, 2016.

14. Chiew YS, Chase JG, Shaw GM, Sundaresan A and Desaive T: Model-based PEEP optimisation in mechanical ventilation. Biomed Eng Online 10: 111, 2011

15. Keenan SP, Sinuff T, Burns KE, Muscedere J, Kutsogiannis J, Mehta S, Cook DJ, Ayas N, Adhikari NK, Hand L, et al; Canadian Critical Care Trials Group/Canadian Critical Care Society Noninvasive Ventilation Guidelines Group: Clinical practice guidelines for the use of noninvasive positive-pressure ventilation and noninvasive continuous positive airway pressure in the acute care setting. CMAJ 183: E195-E214, 2011.
16. Łochowski MP and Kozak J: Video-assisted thoracic surgery complications. Wideochir Inne Tech Malo Inwazyjne 9: 495-500, 2014.

17. Shao W, Xiong X, Chen H, Liu J, Yin W, Li S, Xu X, Zhang X and He J: Long-term survival outcomes of video-assisted thoracic surgery for patients with non-small cell lung cancer. Chin J Cancer Res 26: 391-398, 2014.

18. Freeman RK, Al-Dossari G, Hutcheson KA, Huber L, Jessen ME, Meyer DM, Wait MA and DiMaio JM: Indications for using video-assisted thoracoscopic surgery to diagnose diaphragmatic injuries after penetrating chest trauma. Ann Thorac Surg 72: 342-347, 2001.

19. Lowdermilk GA and Naunheim KS: Thoracoscopic evaluation and treatment of thoracic trauma. Surg Clin North Am 80: $1535-1542,2000$

20. Yang J, Xia Y, Yang Y, Ni ZZ, He WX, Wang HF, Xu XX, Yang YL, Fei K and Jiang GN: Risk factors for major adverse events of video-assisted thoracic surgery lobectomy for lung cancer. Int J Med Sci 11: 863-869, 2014.

21. Ono Y, Ohta Y, Matsumoto G, Kim S, Yokota H and Sakamoto A: [Case report of anesthesia with veno-veno extracorporeal membrane oxygenation (V-V ECMO) during one-lung ventilation for acute respiratory distress syndrome (ARDS) complicated with severe sepsis due to spontaneous esophageal rupture]. Masui 61: 1137-1140, 2012.

22. Salati M and Rocco G: The uni-portal video-assisted thoracic surgery: achievements and potentials. J Thorac Dis 6 (Suppl 6): S618-S622, 2014. 